\title{
Revising the "One-Shot" through Lesson Study: Collaborating with Writing Faculty to Rebuild a Library Instruction Session
}

\author{
Shevaun E. Watson, Cathy Rex, Jill Markgraf, Hans \\ Kishel, Eric Jennings, and Kate Hinnant
}

The one-shot library instruction session has long been a mainstay for many information literacy programs. Identifying realistic learning goals, integrating active learning techniques, and conducting meaningful assessment for a single lesson all present challenges. Librarians and English faculty at one college campus confronted these challenges by participating in a year-long lesson study, a process of collaboratively planning, observing, and assessing a single lesson. By collectively identifying goals and priorities, designing and redesigning the lesson, and assessing outcomes through observation, surveys, and focus groups, librarians and teaching faculty negotiated varying expectations and demands for providing one-shot library instruction.

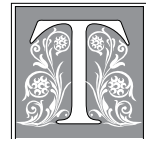

he one-shot library instruction session is a routine occurrence at many academic libraries. Librarians strive to teach some basic research skills with the awareness that the one-shot instruction session is not ideal for meaningful retention or transfer of this knowledge to students' actual research experiences. These one-time, librarian-led presentations, which are developed to meet the needs of the first-year composition or other introductory-level course, are ex- pected to both acquaint students with library services and teach them "how to research," including everything from searching the library catalog to using various databases to discerning types and quality of sources. Not surprisingly, such instruction sessions can easily overwhelm students with their jam-packed, whirlwind dispersal of information, and they can frustrate and overburden the librarians tasked with teaching them. Additionally, such instruction sessions are often unable to incorporate active

Shevaun E. Watson is Assistant Professor of English and Composition Director, Cathy Rex is Assistant Professor of English, Jill Markgraf is Associate Professor and Head of Research E Instruction, Hans Kishel is Assistant Professor and Research E Instruction Librarian, Eric Jennings is Assistant Professor and Instruction \& Outreach Librarian, and Kate Hinnant Associate Lecturer of English, all at University of Wisconsin-Eau Claire; e-mails: watsonse@uwec.edu, rexcj@uwec.edu, markgrjs@uwec.edu, kishelhf@uwec. edu, jenninge@uwec.edu, hinnanks@uwec.edu. (C) 2013 Shevaun E. Watson, Cathy Rex, Jill Markgraf, Hans Kishel, Eric Jennings, and Kate Hinnant, Attribution-NonCommercial (http://creativecommons. org/licenses/by-nc/3.0/) CC BY-NC. 
learning techniques to accommodate the various learning styles of students, or to foster any sort of collaborative environment.

In 2010 and 2011 faculty from both McIntyre Library and the English Department at the University of Wisconsin-Eau Claire worked to alleviate this twopronged dilemma of one-shot library instruction - the overstuffed nature of the lessons and the lack of collaborative, interdisciplinary input in designing and running them - through a relatively new mode of inquiry in American education: the lesson study.

\section{Literature Review}

\section{One-Shot Library Instruction Sessions}

While there has been some research and discussion about the pedagogical underpinnings and structure of such one-shot instruction sessions, there has not been much discussion about the collaborative, interdisciplinary opportunity the reexamination and reformulation of these one-shot instruction sessions could provide. Though there have been examples of innovation with one-shot library instruction sessions, they do not always fully challenge the orthodoxies of library instruction. The University of Minnesota, for example, has expanded the one-shot instruction session to a highly successful series of workshops called Unravel the Library that has been quite well received on the campus. ${ }^{1}$ These three discrete instruction sessions that cover orientation to the library, finding books and articles, and advanced searching each run for approximately seventy-five minutes and teach library and information literacy skills in manageable chunks that contain information "students 'need to know' rather than simply [skills that are] 'nice to know.'"'2 This strategy, while successful, did not incorporate collaboration with the various disciplines that use and depend upon the library instruction sessions or actively engage students in collaborative learning at the level that we sought; it is a singular response based on librarians' perceptions, expectations, and assessments of the instruction's success.

Other studies have tackled the challenge presented by incorporating collaborative student learning into a one-shot library instruction session. The University of Wisconsin-La Crosse has had much success with restructuring library classrooms and the instructors' conceptions of how a library instruction session should look to create sessions that encourage collaborative, experiential learning. These instruction sessions direct "students to construct their own paths to knowledge through socially-relevant, peer-based learning experiences" rather than depending on instruction sessions in which the librarian demonstrates an activity and students attempt to replicate it. ${ }^{3}$ Again, UW-La Crosse has seen marked success with such instruction sessions that prove to be "effective, positive experiences in which students learned well together and met classroom objectives." 4 These one-shot instruction sessions focused on increasing the involvement and active learning of the participants, but they did not have as their purpose the revamping of content and structure of the one-shot library instruction session or inviting interdisciplinary collaboration of faculty to do so.

In discussions about rethinking library instruction models, including the one-shot library session, assessment has become a key component. While some studies describe discrete assessment exercises, such as preassessments and in-class assessments, ${ }^{5}$ others take a more holistic approach. SUNY Geneseo librarians incorporated pre- and post-lesson assessments into a robust process, "closing the assessment loop" by using their analysis to change both their goals and instruction. ${ }^{6}$ Similarly, the Information Literacy Instruction Assessment Cycle (ILIAC), as outlined by Megan Oakleaf, provides a seven-stage plan for collecting and interpreting assessment data and enacting changes. ${ }^{7}$ 


\section{Understanding Lesson Study}

Lesson study is done by collaborative groups of teachers who begin by examining textbooks, standards, and current methods for conveying essential concepts to students in a single lesson. Teachers then "plan, observe, and analyze actual classroom lessons, drawing out implications both for the design of specific lessons and for teaching and learning more broadly." ${ }^{8}$ Specifically, lesson study is an examination of practice that challenges teachers to examine their goals for a lesson as well as student response to them. Lesson study is "inherently collaborative, since teachers work together with a common purpose and draw from one another's experience and expertise." ${ }^{\prime 9}$ The process of lesson study involves collaborating with fellow teachers to identify goals, plan the lesson, teach and observe the lesson, discuss findings, and revise the lesson (see figure 1). The traits of lesson study-intense investigation of the efficacy of a single lesson and the collaboration of multiple teachers to do so-make it especially useful for surmounting the difficulties posed by a particular lesson, such as the one-shot library session.
Lesson study is a professional learning approach that was developed in Japan and has been used there for decades as a method to move from the idea of "'teaching as telling to teaching for understanding'. "10 It gained the attention of educators across the globe in 1999 when it was commended as "a way to build a professional knowledge base for teaching and to improve teaching and learning" by researchers on the Third International Math and Science Study. ${ }^{11}$ Currently, most lesson studies are conducted by teachers in elementary, middle, and secondary schools, with some of the most notable and consistent activity occurring in California in the San Mateo-Foster City School district elementary schools under the direction of Catherine C. Lewis, a specialist in lesson study pedagogy and development in the United States. ${ }^{12}$ Unfortunately, lesson study at the postsecondary level has yet to catch on the way it has with primary school educators. As a whole, the idea of lesson study has not made its way into college-level teaching practices in any significant manner, although the University of Wisconsin (UW) System has embraced this method

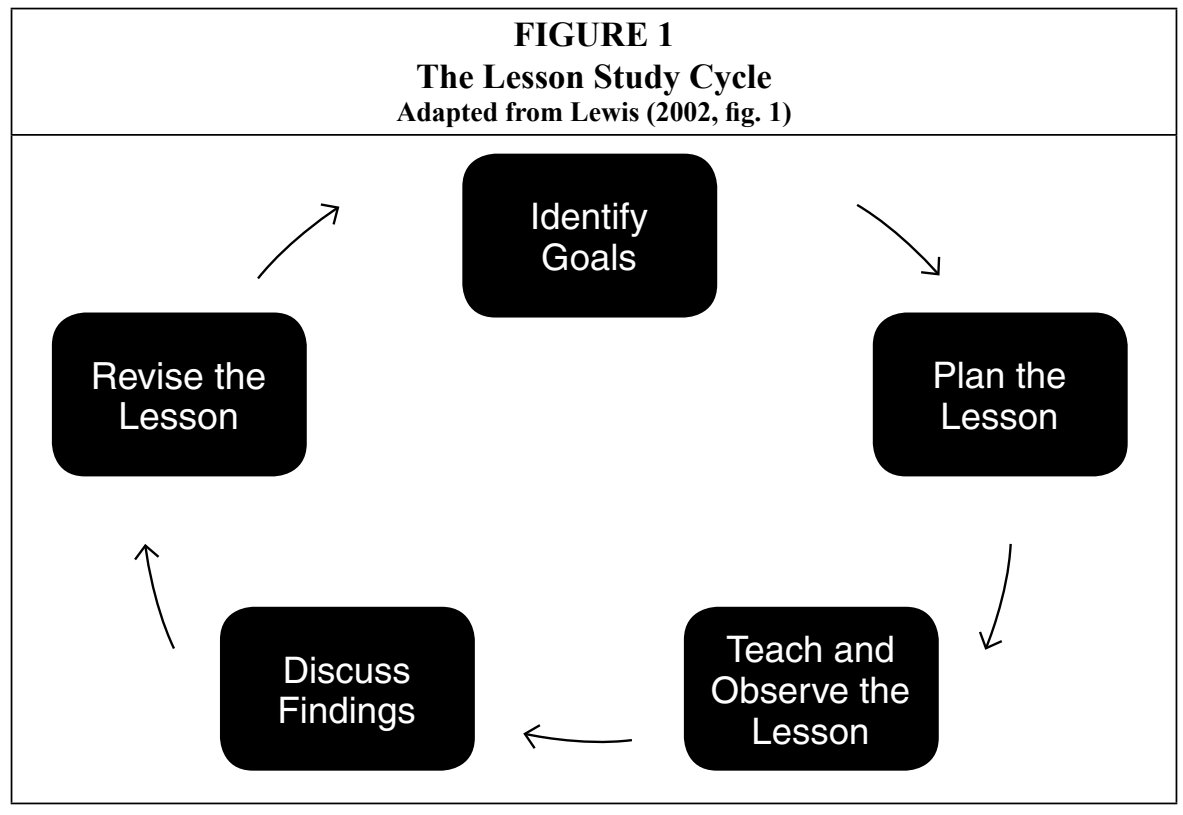


of pedagogical reflection and revision. One of the first college-level lesson studies was conducted by the Department of Mathematics, Statistics and Computer Science at the University of Wisconsin-Stout, and several other UW campuses have undertaken similar lesson study cycles. ${ }^{13}$ The lack of attention to lesson studies at the college level is especially surprising, because this methodology helps teachers refocus on assessing the effectiveness of instruction rather than the performance of the teacher. ${ }^{14}$ Typically, librarians must rely on student feedback that ultimately pertains more to librarian performance than to any meaningful learning. Lesson study is a powerful tool that allows the librarian to focus on the process of teaching and learning rather than on how well he or she engaged with the audience. Moreover, because of the collaborative nature of lesson study, it allows librarians to work closely with faculty as partners in teaching.

\section{Lesson Study in Academic Libraries}

To date, the only documented uses of lesson study in academic libraries were at the University of Michigan and at UW-La Crosse. At Michigan, librarians focused their lesson study on teaching "Search Tools," an implementation of the MetaLib federated search software from ExLibris. ${ }^{15}$ Lesson study participants were librarians from four different libraries whose goal was to create a flexible, thirty-minute lesson teaching "Search Tools" that could be used for different audiences. Librarians ran the lesson study three times and, through the process of revision that is essential to lesson study, developed handouts and an animated PowerPoint presentation to help define "Search Tools." At UW-La Crosse, librarians recognized the potential value of lesson study assessment for the one-shot library instruction session and worked with their Communications Studies faculty to conduct a lesson study of library instruction. ${ }^{16}$ Students worked in groups to research a topic provided by the librarian. Each student was assigned a role in the group, and each group completed a research log with prescribed steps. The lesson included many steps, such as introducing students to the library website and the library catalog, teaching students to choose and search appropriate library databases, providing strategies for evaluative thinking, introducing sources for statistics and quotations, and defining scholarly publications. Through both of these lesson studies, librarians were able to observe student behavior, measure learning outcomes, and identify areas for future modification.

\section{Methodology}

At UW-Eau Claire, we conducted a lesson study starting in 2010 with the goals of overhauling the content of our one-shot library instruction sessions and collaborating as cross-disciplinary faculty in the process. Like the UW-La Crosse faculty, we aimed to develop a lesson that was interactive and customized; unlike the UW-La Crosse lesson study, where students worked with sample topics assigned by the librarian, our study worked with students who had already selected individual research topics for their firstyear composition course, English 110. We, UW-Eau Claire library and English 110 faculty, undertook a lesson study to design a single fifty-minute session aimed to teach specific, identified research skills. Our goal was to create a template that could be modified for varying research topics and class needs, accompanied by a detailed description to give English 110 instructors a realistic sense of what is achievable in a one-shot instruction session.

\section{Goal Setting}

We formed a lesson study group in January 2010, composed of three English faculty and four library faculty. After familiarizing ourselves with lesson studies, we sought to identify the main goals of this session. Using the Association of College and Research Libraries' Information Literacy Competency Standards for Higher 
Education for guidance, ${ }^{17}$ the group isolated nine desired goals on which to focus:

- an awareness of hierarchies of information

- $\quad$ an understanding of differences between key word and subject heading searching

- the ability to refine searches on basis of results

- an understanding of citation chasing

- an understanding of where to go for different types of sources

- the ability to recognize and demonstrate transferability of search skills

- the ability to replicate searches

- the ability to document successful results

- the ability to access the actual source

In a process that spanned several weekly meetings, we discussed what these goals meant, how they might be demonstrated, and what could be accomplished in a fifty-minute instructional session. Coming to the realization that the initial list of goals was too ambitious for such a short class period, we narrowed our goals. We identified as the overarching outcome that "students will be able to construct and implement effective search strategies with an awareness of a variety of search systems." From there, we selected two goals for the lesson study session: 1) students will be able to determine where to go to search for different types of resources; and 2) students will be able to recognize and demonstrate transferability of search skills. Other goals, we decided, should be subsumed in these goals or addressed in "prerequisite" activities preceding the library instruction session. We recommended that two class periods of English 110 be devoted to meeting these prerequisites: evaluating sources, narrowing topics, and conducting background research. The lesson study group used several meetings to plan the prerequisite activities and to design the session itself.

\section{Planning the Initial Lesson}

We selected an English 110 section and a librarian for the lesson study session, and in keeping with the lesson study model, other members of the group observed. We opted for a section that included a two-hour class period, as this provided adequate time for the fifty-minute lesson and follow-up assessment. In designing the lesson, we focused on tying instruction to the stated goals, incorporating interactivity and exploration, and providing effective and concise search examples for demonstration. The lesson plan (see appendix A) began with a brief welcome to the library. Then, using the sample topic of bullying on the Internet, the librarian would demonstrate a catalog search, followed by a search in a multidisciplinary database. This portion of the lesson would last fifteen to twenty minutes. The next fifteen to twenty minutes would be devoted to a collaborative activity in which students would be assigned partners and given worksheets (see appendix B) to complete. Students would then interview their partners about their topics, jotting down keywords as they listened. After both partners shared their topics, students would search on their partners' topics within the catalog and article databases to find one relevant resource for their partner and record enough information about the source so that the partner would be able to locate it. By searching their partners' topics rather than their own, we believed that students would remain on task because they would be accountable to their partners. We also hoped they would be more cognizant of the research process itself rather than get caught up in their own topics. Our aim in having students document the sources they found for their partners was to encourage them to record information necessary for replicating the search. During this activity, the librarian would observe the students to gather examples for the discussion that would make up the final ten minutes of the session. For the discussion, the entire class would come together to talk about their 
search experiences, successes, challenges, and possible solutions. This discussion portion was a crucial element of the lesson plan because it would allow the librarian to present other research strategies and concepts not previously demonstrated.

\section{Teaching and Observing the Lesson}

The session was executed as planned in spring 2010. A unique feature of the lesson study assessment technique is the presence of several observers during the session. In lesson studies, observers are directed to focus on and record the activities of the students as the lesson unfolds. Several observers are placed throughout the classroom, where they can hear student discussions, see computer screens, note activity, and offer a closer look at student behaviors than what can typically be noticed by the librarian. For our initial lesson study, five observers from the group were placed strategically around the room, joined by two guest observers from another UW university.

\section{Discussing the Lesson Findings}

After the lesson study was delivered for the first time, we gathered to discuss our observation notes. At that time, we also reviewed the data collected from students after the lesson, including feedback forms, student worksheets, and focus group comments. There were three major findings that emerged from this process. One of the chief insights from the initial run of the lesson study session was that it was too top-heavy with librarian presentation. Our goal of providing an active learning experience was ultimately thwarted by nearly twenty minutes of lecture and demonstration. A second problem that became apparent to us was that our instructions to the students were unclear. Observers noticed that students were unsure of when to follow along on the computer and when to watch during the presentation. Finally, the students were unconvinced about the value of searching for information for their partner when all they wanted to do was search for their own topic.

\section{Revising the Lesson}

To ameliorate these problems, we revised the lesson study plan in the summer and fall of 2010. We improved the lesson in multiple and significant ways. First, we clarified instructions for students and explicitly verbalized the rationale for searching on their partner's topic. Second, the librarian-led section was split into two parts, thus breaking up lecture and demonstration into shorter and more usable parts. In the revised lesson (see appendix C), we planned for the librarian to present briefly on how to use the library catalog. The students would then immediately begin to work in pairs: sharing topics, generating keywords, and searching for a book or other catalog resource for one another (see appendix D). After the catalog demonstration, the librarian would lead a five-minute discussion on the relative successes and failures of the students' searches. Following that, there would be a short introduction to the article databases. A third change was to have the students work together at this point to search for relevant articles for both partners' topics. We retained the final discussion as the conclusion to the session. Taken together, these revisions increase opportunities for collaborative and active learning, deepen students' understanding of distinctions between search tools and source types, and foster the transferability of search skills. We ran the revised lesson study in spring 2011. This second iteration of the lesson was conducted by a different librarian and with a different English 110 class.

\section{Results}

\section{Observations}

The revised lesson addressed some issues raised in the first lesson, most notably student confusion over the instructions. Many observations of the second iteration of the lesson echoed those of the first. To illuminate these observations, we will describe the second lesson in greater detail. Students in the second iteration of the lesson were initially focused on the librarian's demonstration of the library catalog, some 
following along on their own computers and some listening and watching. After about seven to ten minutes, students began visibly fidgeting in their chairs, distracting themselves with cell phones and other accoutrements in their backpacks. Several students began searching the catalog on their own topics. By the time the librarian introduced and transitioned to the peer activity, the students seemed ready to move on. They immediately and enthusiastically engaged in conversation with their partners, and observers noted that, overall, the conversations were on topic. Students discussed research topics with their partners, generated keywords, and searched the catalog. Most students moved through these steps before being prompted to do so by the librarian, indicating that more time had been budgeted for some segments of the lesson than was necessary. Some students moved on to databases and began searching there as well during the catalog portion of the lesson. When they were brought back together to discuss their experiences, the students who experienced problems in finding relevant resources were forthcoming with their frustrations. This opened up an opportunity to discuss additional strategies for searching the catalog, such as using broader terms and exploring additional content in catalog records. The unfortunate layout of the classroom locates the teaching station, and thus the teaching librarian, in a corner of the room. While most students were engaged during this discussion, the students in the furthest corner from the librarian and the teaching station were whispering among themselves and less attentive to the discussion, suggesting that the librarian may want to employ tactics to draw in students in the far reaches of the room such as moving around the room.

The students were less inclined to sit inactively watching the second demonstration portion of the lesson, which was on searching databases. This demonstration was considerably shorter than the catalog demo, but students began searching on their own topics as the librarian was talking. While the revised lesson stipulated that students would work with their partners during this segment of the lesson, alternating between topics, most students worked independently on their own topics, but did continue communicating with their partners about their findings. The group discussions about what students experienced during database searching again elicited comments and questions, particularly among those who experienced some frustration.

\section{Student Feedback}

We asked students to provide feedback on the lesson through both a survey and subsequent focus groups (see appendices $\mathrm{E}$ and F). Their comments reinforced and supplemented observations. In the student feedback survey, a number of students identified keyword search strategies as the most useful aspect of the lesson. One student commented, "I thought that using new keywords to come up with different topics was the most helpful tip I learned." This concept was reiterated in a student comment on peer activity in which he/she said, "Having someone else look at my topic so I could get a different point of view and ideas of how to search differently [was the most useful thing about the library instruction session]." A number of students also mentioned that they really liked the peer activity, with one student commenting that the most useful part of the lesson was "getting someone elses [sic] perspective on my topic-found different terms to use throughout my research." During the focus group, a student commented that the partner work was helpful because "you got to have two people searching on your topic in a collaborative way. Two different minds [were] working on the same idea." The survey verified the feelings articulated by students in the open-ended portion of the survey and focus groups; 86.2 percent of the students strongly or somewhat agreed that searching for a topic that wasn't their own was very helpful in learning how to do research. 


\begin{tabular}{|c|c|c|c|}
\hline \multicolumn{4}{|c|}{ TABLE 1 } \\
Searching for a Topic that was \\
Not my Own was Very Helpful in \\
Learning How to do Research
\end{tabular}

The time that was given in class to work on searching was one of the key benefits noted about the session: "We were actually given time to work right after being taught which made it easier to understand," noted one student. Overall, 86.2 percent of students found that as a result of the lesson that they would "be able to utilize Library resources more effectively."

\begin{tabular}{|c|c|c|c|}
\hline \multicolumn{4}{|c|}{ TABLE 2 } \\
As a Result of this Session, \\
I Will be Able to Utilize Library \\
Resources More Effectively
\end{tabular}

The survey and focus groups brought forth some constructive criticism as well. A handful of students did not like the partner activity. This was clearly articulated in the focus groups by one student who said that it was difficult to search for his partner's topic since he was not a mind reader and thus did not know exactly what his partner was searching for. Another student wished she had class time to work on her own topic rather than someone else's. Although students appreciated the time for exploration in class, a number of students expressed the desire for even more. "[I would like a] little more time when trying to find sources for my partner. I was only beginning to scratch the surface of the possible info on their topic." Other students commented that the instruction could have gone more in depth, saying, "Most of the things mentioned I already knew about so maybe show some things that we might not know about." Another said that he/she would have liked "more explanation on how to search such as more tips on how to narrow more or how to find what I'm looking for." Some students wanted a "more difficult example, something that does not necessarily return articles or books right away, requires more difficult searching." Because this was a spring semester class, many of the students may have already had library instruction in a different class or had previously interacted with library resources for other classes' research assignments. Additionally, students came to the session with a little more background in using the library than the typical English 110 student, thanks to an enthusiastic teaching assistant who was not only a library science minor but also a student assistant at the library's reference desk. Thus, one student commented in the focus group that "our TA had already covered that stuff in class."

\section{Student Worksheets}

To further assess outcomes of the lesson, we reviewed students' worksheets to see if they were successful in identifying sources relevant to their partners' topics. By analyzing the students' topics and the titles of the sources found, we determined that 89.7 percent of students identified sources that were relevant to the topics. No students recorded irrelevant or inappropriate resources. Those who failed to record a relevant source did not complete that portion of the worksheet, for reasons unknown. It may be that, as some students noted, they did not have enough time. Some students were observed emailing results to themselves or to their partners, and it may be that they found it superfluous to write down the citation information as well.

\section{Discussion}

We all concur that the process of going through the lesson study was ultimately 
more valuable than the resulting lesson plan. There were several significant insights gleaned from this experience. First, the opportunity to observe student behaviors during an instruction session and to gather frank student feedback has impacted how the librarians teach. The library faculty gained a new awareness of their own teaching styles and classroom dynamics and have begun transitioning many of their classes from lecture-based learning to a more active, involved classroom. Even those librarians who had previously prided themselves on incorporating active learning techniques into their instruction sessions were confronted with the reality that they still talked too much. In the continuing reflection and revision that has occurred since the second iteration of the lesson, librarians have reduced the total demonstration time to roughly six minutes, leaving twenty-five minutes for the partner activity and research and twelve to fifteen minutes for discussion. Transitioning to this model of teaching may not be seamless for librarians accustomed to other practices. Relegating most content from a well-planned and relatively predictable presentation to a more extemporaneous question-and-answer session can be unsettling for librarians who already feel they have too much to cover in too little time. Librarian comments during the session suggested that the lesson felt rushed, whereas student behaviors and subsequent comments suggest that students did not share that impression. The librarians who participated in the lesson studies reported that having the opportunity to play the role of teaching librarian as well as observer in the lesson study was extremely useful in understanding the disconnect between the librarian's and the students' perceptions of time.

The second main insight comes from the discussion components of the lesson plan. Observations, student engagement, and student feedback suggest that the postsearching discussions were extremely valuable segments of the lesson. Maximizing the value of these discussions requires that librarians hone certain skills. Rather than coming to a session with carefully prepared examples and demonstrations, librarians must adapt to a teaching scenario in which they exercise their extemporaneous skills. During the crucial discussion segment of the lesson, librarians must strategically elicit student search examples that illustrate content traditionally front-loaded in lecture and demonstration. Effective discussion requires the librarian to actively walk around the room, observe student search behaviors as they search, and gather examples that illustrate search techniques and challenges. Some librarians expressed discomfort in "peering over students' shoulders" as they worked, but a simple explanation to the students ahead of time that they will be doing so may be sufficient to put both librarians and students at ease. Using real examples of difficulties encountered by the students will enable the librarian to take the discussion to the more advanced level desired by the students.

Third, we found that working as experts across disciplinary boundaries to plan the lesson enabled us to understand various perspectives on our students' complex information literacy needs. Out of this collaboration grew the intentional integration of specific information literacy instruction into the first-year composition course. But even more important is the sustained collaboration that has emerged between the library and English department beyond the lesson study. The first-year writing curriculum was being revamped at the same time that the lesson study was being conducted; as a result, lesson study librarians were invited to help plan the integration of library instruction into the new curriculum. Products of the lesson study, including the revised one-shot library instruction lesson plan and the prerequisite activities, formed the basis of that integration. Through the lesson study, librarians and English faculty developed a common language and shared understanding of what can reasonably be expected during a fifty-minute instruction session. 
Finally, we realized this lesson study pertained to one-shot library instruction sessions beyond the first-year composition course, pushing us to address the limitations of the one-shot model overall. For example, we identified and designed the prerequisite activities and bracketed off concepts that could be conveyed through online tutorials and videos. These discussions prompted the development of a menu of library instruction options that will enable instructors to pick and choose the concepts or skills they wish to have included in a library instruction session. Librarians expressed long-held frustration with requests for library instruction sessions that ask them to cover unrealistic amounts of material in one class period. But they also admitted to their own tendency to perpetuate the impression that they could effectively accommodate such requests. Lesson study provided a model for librarians to have conversations with faculty in all disciplines about what can realistically be covered in a fifty-minute session.

As librarians further develop this menu of instruction options, they have an alternative way to meet the requests of faculty and the information literacy needs of students. Word of the lesson study collaboration has spread on campus, and librarians are now being approached by faculty in other disciplines interested in conducting similar studies to improve the integration of information literacy into their curricula. Armed with an enhanced ability to communicate with faculty, student feedback and assessment data, and a growing array of supplementary instruction tools, librarians can confidently respond when instructors request a one-shot library instruction session.

\section{Appendix A}

\section{Initial English 110 Library Instruction Lesson Study Outline}

\section{(5 min.) Welcome to the library}

In this session we will explore some research tools. We'll start with a quick demonstration of searching the library catalog and a library database for journal articles, and then you will begin working on your topics with the help of a partner. At the end we will come back together to discuss our research experiences. There are more research tools and strategies available to you than we will be able to cover today, so please remember one of the most important library resources available to you: people. Library staff are here to help you when you have questions during your research process. You can stop by the reference desk, reach us by phone, chat, e-mail, or set up an appointment with a librarian.

\section{(5 min.) Catalog search}

My research topic looks at the phenomenon of bullying on the Internet.

Catalog (from homepage):

- $\quad$ expect to find books, videos, other media, government documents, not journal articles

- enter: bullying Internet (note that it's not a question or phrase, just contentbearing words)

- first 3 results mention cyberbullying, but are not consistent in how the term is written

- Click on first result to illustrate subject headings (standardized spelling of cyberbullying, broader terms), mention location information and call number 


\section{(5-10 min.) Database search}

Use databases to find journal articles, newspaper articles, magazine articles, usually more current information than books.

- Databases by topic: have students choose a topic (discipline) likely to include information on cyberbullying

- Multidisciplinary databases vs. specialized databases

- From list of recommended databases, select Academic Search Complete

- Enter: cyberbullying

- Discuss results:

- click on record for abstract and headings

- Fulltext vs. Find It

- methods for limiting search results (e.g., Scholarly only or add search term like "middle school")

\section{(15-20 min.) Exercise (handout outlining steps)}

- (2 min.) Intro to activity: Now you get to work on your search topics. [Assign partners. Distribute worksheet.]

Put your name on the sheet and exchange worksheets with your partner. Now that you have your partner's sheet, put your name down for "searcher." First, one of you will each describe your topic to your partner. You will have about 2 minutes to do this, then I will ask you to switch and the other person in your pair will describe his/her topic. Write down your partner's research topic. As you listen to your partner, jot down words, phrases and ideas that you hear-as well as any synonyms or related ideas that come to you. Ask clarifying questions if you need to, as you will be doing a search on your partner's topic.

- (2 min.) First partner describes topic. Call the switch.

- $\quad$ (2 min.) Second partner describes topic.

- $\quad$ (7 min.) Search on partner's topic. Write down steps and results.

- (3 min.) Partners share results

- Can you tell what the information source is?

- Does it look like it will be useful?

- Do you have enough information to find it?

\section{(10 min.) Entire group comes together to discuss results}

- Librarian asks focused questions such as:

- Whose partner came up with what looks like THE perfect source for your topic?

- $\quad$ Did anyone have trouble finding anything for their partner?

- Did anyone search the library catalog and come up with nothing on their topic?

- What challenges did you face in searching for a journal article?

- Librarian comments on observations.

\section{Wrap up.}




\section{Appendix B}

\section{Initial Lesson Study Worksheet}

ENG 110: Library Research

Name

Name of your partner:

As your partner describes his/her research topic, jot down some of the words and ideas you hear.

Research topic:

Keywords:

Now you can begin looking for one really good source for your partner's research. It is up to you to determine whether the source is a book, journal article, etc.

Where did you search?

Record the steps you took to find the source:

List the source you found. Record enough information so that your partner can find it again.

\section{Appendix C}

\section{Revised English 110 Library Instruction Lesson Study Outline}

\section{(2 min.) Welcome to the library}

In this session we will explore some research tools for finding books, journal articles, and other media that are necessary and appropriate for doing college-level research.

- Distribute exercise sheet.

\section{(20 min.) Catalog search}

- Please watch while I briefly demonstrate how to get to the library catalog. This is the tool we use for finding books, videos, other media, government documents

- Sample search: My research topic looks at the Native American mascot controversy.

- Search "Native American mascots" and demonstrate moving from list of results to an individual record. Explain that the record contains information/links that will lead you to other resources.

- $\quad$ Exercise 1 (12 $\mathrm{min}$. total)

- $\quad$ (4 min.) First you will each describe your topic to your partner. You will have about 2 minutes to do this, then I will ask you to switch and the other person in your pair will describe his/her topic. As you listen to your partner, jot down words, phrases, and ideas that you hear-as well as any synonyms or related ideas that come to you. Ask clarifying questions if you need to, as you will be doing a search on your partner's topic.

- $\quad(2$ min.) Brainstorm keywords for your partner's topic and write them on the 
exercise sheet.

- $\quad$ Next you will be searching for your partner because 1) you bring a different perspective to the topic and 2) it gives you the opportunity to step back from your own topic for a moment and focus on search strategies.

- $\quad$ (4 min.) Search in the catalog for a book or other source on their topic. On the exercise sheet, write down the information about one promising result you found (if any).

- $\quad(2 \mathrm{~min}$ ) Share your result with your partner. Discuss how you found the item. What words did you type in? Ask your partner if it looks useful. Do this for both search topics.

\section{- Discussion (5 min.)}

- Whose partner came up with what looks like THE perfect source for your topic?

- $\quad$ Did anyone have trouble finding anything for their partner?

- What strategies did you use? (search strategies on handout)

- Discuss strategies for moving from one good result to another (subject headings, call numbers). Broadening a topic.

\section{(20 min.) Database search}

(3 min. demo)

- Please watch while I briefly demonstrate how to get to the library databases. These are the tools we use for finding journal articles, newspaper articles, and magazine articles.

- Multidisciplinary databases vs. specialized databases

- Databases by topic: have students choose a topic (discipline) likely to include information on Native American Mascots \& Team Names

- Enter: Native American Mascots

- Discuss results:

- click on record for abstract and headings

- $\quad$ Exercise 2 (10 min. total)

- Go back to homepage

- $\quad$ (4 min.) Now you will work with your partner to search on your topics. Identify which partner will do the searching first. Direct students to Academic Source Complete and ask them to work together to find an article on the other partner's topic.

- $\quad$ (4 min.) Switch so that the second partner now does the searching. Partners work together to find an article on the second topic.

- $\quad$ (2 min.) Now you get to work on your search topics together. Work with your partner to find an article on your topic. Then switch to find article on your partner's topic.

- $\quad$ Discuss (7 min.)

Librarian asks focused questions such as:

- Whose partner came up with what looks like THE perfect source for your topic?

- Did anyone have trouble finding anything for their partner?

- What challenges did you face in searching for a journal article?

- How can one good source lead you to others?

- Did you have trouble getting the actual article? 


\section{(5 min.) Wrap up}

There are many more research tools and strategies available that will be valuable for this research assignment as well as future ones. Library staff are here to help you when you have questions during your research process. You can stop by the reference desk, reach us by phone, chat, e-mail, or set up an appointment with a librarian.

\section{Appendix D}

\section{Revised Lesson Study Worksheet}

ENG 110: Library Research

Your Name

Name of your partner:

1. As your partner describes his/her research topic, take notes.

2. What are some related words that you could also use? (e.g., teens or teenagers, movie or film)

3. Working independently, search in the library catalog for one really good source for your partner's research. Write down enough information so that your partner can find it again:

\section{[wait for further instructions]}

Not finding anything? Try these strategies to modify your search by...

- Broadening • Narrowing

- Parallel concept $\bullet$ Time $\bullet$ Geography

Example: Southern Plantations

Broadening: Estate Farm

Narrowing: Slave-holding plantations

Parallel: South American Coffee Plantations

Time: 18th c. Southern Plantation

Geography: Charleston, S.C. area

4. Working with your partner, search for one really good article for your research topic. Write down enough information so that you can find it again: 


\section{Appendix E}

\section{Results of Revised Lesson Study Feedback ( $\mathrm{N}=29$ )}

I found that searching for a topic that was not my own was very helpful in learning how to do research.

\begin{tabular}{|c|c|c|c|}
\hline Strongly Agree & Somewhat Agree & Somewhat Disagree & Strongly Disagree \\
\hline 3 & 22 & 2 & 2 \\
\hline $10.3 \%$ & $75.9 \%$ & $6.9 \%$ & $6.9 \%$ \\
\hline
\end{tabular}

The Librarian presented information that will be useful to me.

\begin{tabular}{|c|c|c|c|}
\hline Strongly Agree & Somewhat Agree & Somewhat Disagree & Strongly Disagree \\
\hline 11 & 15 & 3 & \\
\hline $37.9 \%$ & $51.7 \%$ & $10.3 \%$ & $0.0 \%$ \\
\hline
\end{tabular}

The Librarian presented information in a clear and concise manner.

\begin{tabular}{|c|c|c|c|}
\hline Strongly Agree & Somewhat Agree & Somewhat Disagree & Strongly Disagree \\
\hline 19 & 9 & 1 & \\
\hline $65.5 \%$ & $31.0 \%$ & $3.4 \%$ & $0.0 \%$ \\
\hline
\end{tabular}

The Librarian covered the right amount of material.

\begin{tabular}{|c|c|c|c|}
\hline Strongly Agree & Somewhat Agree & Somewhat Disagree & Strongly Disagree \\
\hline 11 & 14 & 2 & 2 \\
\hline $37.9 \%$ & $48.3 \%$ & $6.9 \%$ & $6.9 \%$ \\
\hline
\end{tabular}

I will refer back to the materials \&/or webpage developed by the Librarian.

\begin{tabular}{|c|c|c|c|}
\hline Strongly Agree & Somewhat Agree & Somewhat Disagree & Strongly Disagree \\
\hline 13 & 11 & 3 & 2 \\
\hline $44.8 \%$ & $37.9 \%$ & $10.3 \%$ & $6.9 \%$ \\
\hline
\end{tabular}

The pace of the session was:

\begin{tabular}{|c|c|c|}
\hline Just Right & Too Fast & Too Slow \\
\hline 22 & 4 & 3 \\
\hline $75.9 \%$ & $13.8 \%$ & $10.3 \%$ \\
\hline
\end{tabular}

As a result of this session, I will be able to utilize Library resources more effectively.

\begin{tabular}{|c|c|c|c|}
\hline Strongly Agree & Somewhat Agree & Somewhat Disagree & Strongly Disagree \\
\hline 9 & 16 & 2 & 2 \\
\hline $31.0 \%$ & $55.2 \%$ & $6.9 \%$ & $6.9 \%$ \\
\hline
\end{tabular}




\section{Appendix F}

\section{Student Responses to Questions on Feedback Form from Revised Lesson}

Study [Note that these are not edited for spelling or grammatical errors]

\section{What I found most useful about this session was:}

- Getting to hear what other people were using for topics, I still don't know what I want to do.

- $\quad$ Being able to work with someone else to get more feedback and other opinions on what to search for.

- Talking with a peer about my topic.

- Having someone else look at my topic so I could get a different point of view and ideas of how to search differently.

- Partner input.

- Getting someone else's perspective on my topic-found different terms to use throughout my research.

- I thought that using new keywords to come up with different topics was the most helpful tip I learned.

- Narrowing my search help by topic.

- $\quad$ Tips like using related terms. Broaden/Narrow/Parallel.

- Learning how to broaden/narrow my search terms.

- Using other keywords yields new results.

- How to better use the databases.

- The emphasis on using different search terms/keywords. Learning how to find sources from other sources/articles.

- The information on book searches, that was new to me.

- Learning about the online bookshelf.

- Learning about the "online book shelf"

- Showing how to find the differnet .search engins/hosts.

- How to receive call \#s.

- How to find specific items online and how he used examples to show us how to do it.

- Looking at differn search sites and using all of them.

- Learnig more about the library's website.

- Learning new stuff about the McIntyre Library website

- He really explained how to use the system in depth. That was really nice to get a little help.

- The presenter explained where and how to find info explained how to begin searching.

- Having time in class to research my topic.

- We were actually given time to work right after being taught which made it easier to understand.

- $\quad$ Being able to search for topics but I could've done that on my my own :(

\section{What I would like to see improved in future sessions:}

- Most of the things mentioned I already knew about so maybe show some things we might not know about.

- Overall it was pretty helpful!

- More data about youtube. There isn't that much on the online database. But anything related to the presentation, there wasn't anything wrong with it.

- I would like to see more information that I did not already know.

- Ideas that are different than what most people already know. 
- More in depth ideas, everything that was said we have already covered in class felt extremely rushed.

- Overall not helpful.

- Maybe more time to work.

- Little more time when trying to find sources for my partner. I only was beginning to scratch the surface of possible info on their topic.

- Slower lessons.

- Able to use more time in each activity.

- Clearer directions but more work time on own.

- Explain where to go when things aren't available here.

- More explanation of how to search such as more tips and how to narrow more or how to find what I'm looking for ex! Book vs casset tapes.

- How to get a text available when its not in our library.

- Tips about being more specific in searching.

- More help on synonyms for search keywords.

- Provide a more difficult example, something that does not necessarily return articles or books right away, requires more searching.

- Focus more with key terms and how/when to use them.

- What else is available to do / other ways to search for materials online.

- Show the website more indepth.

- Because there is so much info on N.A. mascots it really didn't show what to do if your stuck.

- All I really got out of it was try new words. If that doesn't work what Now? search for own topics!

- I can't think of anything to change. I thought the session went well. 


\section{Notes}

1. Van Houlson, "Getting Results from One-Shot Instruction: A Workshop for First-Year Students," College \& Undergraduate Libraries 14, no. 1 (2007): 89-108.

2. Ibid., 104.

3. Stefan Smith, "Designing Collaborative Learning Experiences for Library Computer Classrooms," College \& Undergraduate Libraries 11, no. 2 (2004): 66.

4. Ibid., 80 .

5. Jonathan Helmke and Brad S. Matthies, "Assessing Freshman Library Skills and Attitudes Before Program Development," College \& Undergraduate Libraries 11, no. 2 (2004): 29-49.

6. Bonnie J.M. Swoger, "Closing the Assessment Loop Using Pre- and Post-Assessment," Reference Services Review 39, no. 2 (2011): 244-59.

7. Megan Oakleaf, "The Information Literacy Instruction Assessment Cycle: A Guide for Increasing Student Learning and Improving Librarian Instructional Skills," Journal of Documentation 65, no. 4 (2009): 539-60.

8. Catherine C. Lewis et al., "Lesson Study Comes of Age in North America," Phi Delta Kappan 85, no. 7 (Dec. 2006): 273.

9. Sonal Chokshi and Clea Fernandez, "Challenges to Importing Japanese Lesson Study: Concerns, Misconceptions, and Nuances," Phi Delta Kappan 88, no. 4 (Mar. 2004): 521.

10. Catherine C. Lewis, "The Essential Elements of Lesson Study," Northwest Teacher 4, no. 3 (2003): 6 .

11. Catherine C. Lewis, "What Is the Nature of Knowledge Development in Lesson Study?" Educational Action Research 17, no. 1 (2009): 95. According to Lewis, Perry, and Muratka, the lesson study literature rests upon two examples of full lesson study cycles from Japan. These studies focused on elementary school teachers using lesson study in math and science education. See: Catherine C. Lewis, Rebecca Perry, and Aki Murata, "How Should Research Contribute to Instructional Improvement? The Case of Lesson Study," Educational Researcher 35, no. 3 (2006): 3. The lesson study literature reflects this in that much of its focus is on $\mathrm{K}-12$ education, $\mathrm{K}-12$ teacher training, and mathematics. See: Elizabeth A. Burroughs and Jennifer L. Luebeck, "Pre-Service Teachers in Mathematics Lesson Study," Montana Mathematics Enthusiast 7, no. 2/3 (2010): 391-400; Roberta Devlin-Scherer, Lourdes Z. Mitchel, and Mary Mueller, "Lesson Study in a Professional Development School," Journal of Education for Teaching 33, no. 1 (2007): 119-20; Jennifer Dubin, "American Teachers Embrace the Japanese Art of Lesson Study," Education Digest 75, no. 6 (2010): 23-29; Noriyuki Inoue, "Zen and the Art of Neriage: Facilitating Consensus Building in Mathematics Inquiry Lessons through Lesson Study," Journal of Mathematics Teacher Education 14, no. 1 (2011): 5-23; Catherine Lewis, Rebecca Perry, and Jacqueline Hurd, "A Deeper Look at Lesson Study," Educational Leadership 61, no. 5 (2004): 18-22; Naomi Robinson and Roza Leikin, "One Teacher, Two Lessons: The Lesson Study Process," International Journal of Science \& Mathematics Education 10, no. 1 (2012): 139-61; W.W. Wilms, "Altering the Structure and Culture of American Public Schools," Phi Delta Kappan (Apr. 2003): 606-13.

12. Lewis et al., "Lesson Study Comes of Age," 273. Lewis has written or coauthored two books on lesson study: Catherine C. Lewis, Lesson Study: A Handbook of Teacher-Led Instructional Change (Philadelphia, Pa.: Research for Better Schools, 2002); Catherine C. Lewis and Jacqueline Hurd, Lesson Study Step by Step: How Teacher Learning Communities Improve Instruction (Portsmouth, N.H.: Heinemann, 2011). Other books on lesson study include: Bill Cerbin, Lesson Study: Using Classroom Inquiry to Improve Teaching and Learning in Higher Education (Sterling, Va.: Stylus, 2011); Lesson Study Research and Practice in Mathematics Education: Learning Together, eds. Lynn C. Hart, Alice Alston, and Aki Murata (Dordrecht, The Netherlands: Springer, 2011); Jennifer Stepanek et al., Leading Lesson Study: A Practical Guide for Teachers and Facilitators (Thousand Oaks, Calif.: Learning Point Associates / NWREL / Corwin Press, 2007); Karin M. Wiburg and Susan Brown, Lesson Study Communities: Increasing Achievement with Diverse Students (Thousand Oaks, Calif.: Corwin Press, 2007).

13. Joy Becker et al., "A College Lesson Study in Calculus, Preliminary Report," International Journal of Mathematical Education in Science and Technology 39, no. 4 (2008): 492.

14. Chokshi and Fernandez, "Challenges to Importing Japanese Lesson Study," 521.

15. Shevon Desai, Marija Freeland, and Eric Frierson, "Lesson Study in Libraries," College \& Research Libraries News 68, no. 5 (2007): 290-93.

16. Galadriel Chilton et al., "Teaching Library Information Literacy Skills to Students Enrolled in an Introductory Communication Course: A Collaborative Study" (unpublished manuscript, Feb. 28, 2007), available online at www.cfkeep.org/html/snapshot.php?id=52676532745991 [accessed 24 November 2010].

17. Association of College and Research Libraries, Information Literacy Competency Standards for Higher Education (Chicago: Association of College and Research Libraries, 2000). 